\title{
Integration of Production and Cost Models in Model-Based Product Development
}

\author{
Kathrin Spütz", Georg Jacobs, Christian Konrad, Christian Wyrwich \\ Institute for Machine Elements and Systems Engineering, RWTH Aachen University, Aachen, Germany \\ Email: *kathrin.spuetz@imse.rwth-aachen.de
}

How to cite this paper: Spütz, K., Jacobs, G., Konrad, C., \& Wyrwich, C. (2021). Integration of Production and Cost Models in Model-Based Product Development. Open Journal of Social Sciences, 9, 53-64. https://doi.org/10.4236/jss.2021.912004

Received: October 4, 2021

Accepted: December 4, 2021

Published: December 7, 2021

Copyright (อ 2021 by author(s) and Scientific Research Publishing Inc. This work is licensed under the Creative Commons Attribution International License (CC BY 4.0).

http://creativecommons.org/licenses/by/4.0/

(c) (i) Open Access

\begin{abstract}
Companies in mechanical engineering are facing an increasingly high cost pressure in international competition. Therefore, in addition to the given technical functionality, cost oriented product design is becoming a dominating factor for the success of a product on the market. For the cost-oriented product design, knowledge from the field of production and controlling is highly relevant. This contribution shows how this knowledge can be formalized and linked to the product model of the engineering department in a model-based product development. This enables engineering departments to access non-domain specific but cost-relevant knowledge at an early stage in the development process. As a result, the product design can already be determined cost-oriented in the engineering department.
\end{abstract}

\section{Keywords}

Model-Based Systems Engineering, Domain Models, Cost Calculation, Production, Knowledge Transfer

\section{Introduction}

Mechanical engineering companies are facing increasing cost pressure due to international competition (Verband Deutscher Maschinen- und Anlagenbauer, 2018; Friedli \& Schuh, 2012). This environmental change is particularly relevant for manufacturing companies in the classical mechanical engineering sector, with a high degree of new and customized designs (Friedli \& Schuh, 2012). For the success of products on the market, cost-oriented design is becoming a dominant factor in addition to the given technical functionality (Ehrlenspiel et al., 2014). In addition, the change towards international competition implies that market needs can no longer be satisfied by products with pre-engineered parts (Anderson \& Pine, 1998). This leads to customized products as well as compo- 
nents and consequently to adjustments in the production of these. Thus, cost calculation is usually only possible after the product has been fully designed. The problem associated with this situation is that the greatest potential for influencing product costs lies in the engineering department. Approximately $70 \%$ of the product costs are determined in this department (Ehrlenspiel et al., 2014; Eigner \& Stelzer, 2009). In contrast, the originators of the main costs are in manufacturing and purchasing. These departments together cause about $69 \%$ of the product costs (Verein Deutscher Ingenieure, 1987; Verband Deutscher Maschinen- und Anlagenbauer, 2006). Consequently, the knowledge about the product cost origin lies in these departments and is usually not available at an early stage for new and adapted designs in the engineering department (Ehrlenspiel et al., 2014). As a result, the engineering department cannot evaluate during the product design, whether the product target costs are met (Ehrlenspiel et al., 2014; Eigner \& Stelzer, 2009). Late cost calculation makes iterations between product development and manufacturing or purchasing likely. This essential problem must be solved by externalizing cost-relevant knowledge through modeling and making it available across departments (Ehrlenspiel et al., 2014). A promising approach is model-based system engineering (MBSE).

\section{Model-Based Systems Engineering}

Current MBSE approaches focus on the use of formalized modeling to support product development (Eigner, Roubanov, \& Zafirov, 2014). This enables the management of increasing product and functional complexity in the development process (Eigner, Roubanov \& Zafirov, 2014). MBSE methods such as SYSMOD (Weilkiens, 2016) and FAS4M (Moeser et al., 2016) as well as the MSE ARCHITECTURE (Zerwas et al., 2021) focus on a function-based product development. Differences between the MBSE approaches lie especially in the way of linking development results and the modeling of fundamental, physical interrelationships (see Figure 1).

The FAS4M (Moeser et al., 2016) method focuses on modeling the fundamental, physical interrelationships via sketches. The linking of these sketches with development results, such as functions, is done via the abstract systems

\begin{tabular}{|l|c|c|c|}
\hline \multicolumn{1}{|c|}{$\begin{array}{c}\text { Requirement } \\
\text { Model }\end{array}$} & $\begin{array}{c}\text { Functional } \\
\text { Model }\end{array}$ & $\begin{array}{c}\text { Logical Model } \\
\text { (fundamental, physical } \\
\text { interrelationships) }\end{array}$ & $\begin{array}{c}\text { Physical } \\
\text { Model }\end{array}$ \\
\hline $\begin{array}{l}\text { FAS4M } \\
\text { Requirements }\end{array}$ & Functions & Sketches & Components \\
\hline $\begin{array}{l}\text { SYMOD } \\
\text { Requirements }\end{array}$ & Functions & - & Components \\
\hline $\begin{array}{l}\text { MSE ARCHITECTURE } \\
\text { Requirements }\end{array}$ & Functions & $\begin{array}{c}\text { Parameters and simple } \\
\text { physical Models }\end{array}$ & Components \\
\hline
\end{tabular}

Figure 1. Comparison of the MBSE methods FAS4M, SYSMOD and MSE ARCHITECTURE in terms of mapping the fundamental physical properties within the logical model. 
modeling language (SysML) relation trace. SYSMOD (Weilkiens, 2016) focuses on the direct function-oriented description of the physical realization without describing the basic, physical interrelations. Thus, the methods FAS4M and SYSMOD do not allow a description of the basic, physical realization via parameters and models. For this reason, the approaches are not suitable for the connection with cost-relevant knowledge in the early development phases. The MSE ARCHITECTURE (Zerwas et al., 2021) with the language profile SysML4FMArch (Drave et al., 2020) focuses on the continuous linking of requirements via functions and principle solutions up to the product. The formalized, functional description of the principle solution via parameters and simple physical models allows the description of basic physical interrelations (Zerwas et al., 2021). Thus, early function-based testing and product design is enabled (Höpfner et al., 2021). The central component of the approach is the solution element, in which the principle solution is linked to all models and workflows of the necessary domains, to describe its behavior. The engineering models and workflows also enable the design and testing of the principle solution with respect to further purposes, such as lifetime.

\section{Research Needs and Methods for the Integration of Production and Controlling Models into the MSE ARCHITECTURE}

Using the MSE ARCHITECTURE, the function-oriented development of products can already be described (Zerwas et al., 2021). However, there is currently a lack of concrete approaches for a function-oriented development considering cost relevant knowledge. Within the scope of this thesis, such an approach is developed by means of a methodical procedure for the integration of production and controlling domain models into the function-oriented MSE ARCHITECTURE. With the help of the models, the production costs already become apparent in the development process and can be compared with the target costs. The procedure consists of the following steps:

1) Building the system model of the product according to the MSE ARCHITECTURE.

2) Extending the MSE ARCHITECTURE metamodel by production and controlling models.

3) Identifying and formalizing relevant production and controlling models.

4) Integrating relevant production and controlling models into the MSE ARCHITECTURE.

The steps of this procedure are presented in the following using a product example. The example is based on the industrial practice of a middle-sized company with a portfolio of conveyor chains.

\subsection{Building the System Model of the Product According to the MSE ARCHITECTURE}

The relevance of the production and controlling models for product cost deter- 
mination mainly depends on the product geometry. For this reason, the principle product design is required. In the MSE ARCHITECTURE the principle geometric design is described within the active surfaces of the solution element. For the conveyor chain product example, a part of the MSE ARCHITECTURE is shown in Figure 2. Initial point of the development is customer-specific, functional requirements, such as the maximum tensile force of the chain. The functional requirements are transferred into a functional product description Conduct Force between Solids. This is realized by the solution elements ClearanceContact and PressContact, which are represented through the active surface set and the physical effect of the solution element. The solution element links the principle solution view with various domain models.

The function-oriented design of the active surface geometry parameters is performed using models from the domain engineering and design workflows in the solution element and the superordinate element-the system solution.

With the help of the function-oriented description in the solutions, products can already be developed and designed in a functional optimized way. The function-oriented design of the solution elements with engineering models is not critical for the success of products, such as the conveyor chain. In order to succeed in competition, the target costs from the requirements must be met for a given functionality. For this purpose, the product costs must already be apparent during development. Consequently, the MSE ARCHITECTURE metamodel must be extended by models that enable cost calculation. These models are located in the domains Production and Controlling.

\subsection{Extending the MSE ARCHITECTURE Metamodel by Production and Controlling Models}

To enable the extension of the MSE ARCHITECTURE by production and

\begin{tabular}{|c|c|c|c|}
\hline Requirements & \multicolumn{3}{|c|}{ Solutions } \\
\hline "Requirement" & \multicolumn{2}{|c|}{ "SolutionElement" ClaeranceContact } & \multirow{2}{*}{$\begin{array}{l}\text { "SystemSolution" } \\
\text { Chain Joint }\end{array}$} \\
\hline & \multirow{2}{*}{$\begin{array}{l}\text { "PhysicalEffect" } \\
\text { HertzianPressure }\end{array}$} & \multirow{2}{*}{$\begin{array}{l}\text { "DomainModel" } \\
\text { Engineering }\end{array}$} & \\
\hline \multirow{2}{*}{$\begin{array}{l}\text { "The chain cost must } \\
\text { not exceed } 125 € \text {." }\end{array}$} & & & \\
\hline & \multirow{2}{*}{$\begin{array}{c}\text { "ActiveSurfaceSet" } \\
\text { geo: CylCyl }\end{array}$} & \multirow{2}{*}{ FEM-Model } & \multirow{3}{*}{$\operatorname{lil}_{1}$} \\
\hline \multirow{2}{*}{$\begin{array}{l}\text { "Requirement" } \\
\text { Traction }\end{array}$} & & & \\
\hline & \multirow{2}{*}{$\begin{array}{c}\text { parts } \\
\text { contact: DiffClaeranceFit }\end{array}$} & \multirow{2}{*}{ FEM-Model } & $4 i$ \\
\hline \multirow{2}{*}{$\begin{array}{l}\text { "The traction force } \\
\text { of the chain must } \\
\text { be at least } 100 \\
\text { kN." }\end{array}$} & & & \\
\hline & $\begin{array}{c}\text { "ActiveSurface" } \\
\text { innercyl: Cylinder }\end{array}$ & $\begin{array}{c}\text { "Workflow" } \\
\text { Design }\end{array}$ & \multirow{2}{*}{$\begin{array}{c}\text { "Component" } \\
\text { CylindricStructure }\end{array}$} \\
\hline & material: struc. steel & \multirow{2}{*}{$\frac{\text { getParameter }}{\downarrow}$} & \\
\hline & & & \\
\hline Functions & outercyl: Cylinder & $\frac{\downarrow}{\text { setParamete }}$ & \\
\hline \multirow{3}{*}{$\begin{array}{l}\text { "ElementaryFunction" } \\
\text { Conduct Force } \\
\text { between Solids } \\
\end{array}$} & \multirow{2}{*}{\multicolumn{2}{|c|}{ "SolutionElement" PressContact }} & \multirow{2}{*}{$\begin{array}{c}\text { "DomainModel" } \\
\text { Engineering } \\
\end{array}$} \\
\hline & & & \\
\hline & \multicolumn{2}{|c|}{ "ActiveSurfaceSet" geo: CylCyl } & \multirow{2}{*}{$\begin{array}{c}\text { "Workflow" } \\
\text { Design }\end{array}$} \\
\hline \multirow{2}{*}{$\begin{array}{l}\text { proxy ports } \\
\text { in } \mathrm{F} \text { in : Force } \\
\text { out } \overline{\mathrm{F}} \text { _out : Force }\end{array}$} & \multirow{2}{*}{\multicolumn{2}{|c|}{$\begin{array}{l}\text { parts } \\
\text { innercyl: Cylinder } \\
\text { outercyl: Cylinder }\end{array}$}} & \\
\hline & & & "Workflow" \\
\hline
\end{tabular}

Figure 2. Function-oriented modeling of a chain joint according to the MSE ARCHITECTURE according to Jacobs et al. (2022). 
controlling domain models, the metamodel of the system solution and the solution element has to be extended. Through the extension is explicitly defined at which point of the MSE ARCHITECTURE the domain models are integrated. The metamodel of the system solution and the solution element already includes the engineering domain models. The models of the domains production and controlling have to be integrated at the same point. This extension of the MSE ARCHITECTURE metamodel is shown in Figure 3 for the solution element.

The production domain models are used in the MSE ARCHITECTURE to plan and optimize the production of the geometry. This production planning is based on the geometry from the principle view of the solution. By planning the production of the geometry, the determination of relevant controlling models and the input parameters for these models is enabled. Purpose of the controlling models is to determine the production costs of the geometry. The structuring of the engineering, production and controlling models within the system solution metamodel is designed similar to the solution element. Only the explicit content of the models differs.

Extending the MSE ARCHITECTURE metamodel by production and controlling models provides a framework for the inclusion of cost-relevant knowledge at an early stage of product development. Depending on the application, the relevant domain models for the production of geometry in the solutions must be identified and integrated.

\subsection{Identification and Formalization of Relevant Production and Controlling Models}

How the identification and architecture-compliant formalization of production and controlling is carried out, is explained on the conveyor chain example in the following. The main focus is the functionally relevant part of the chain-the system solution chain joint.

\subsubsection{Identification of the Relevant Production Models}

The identification of the relevant production models is based on the production planning for the geometries of the system solution. In the running example of

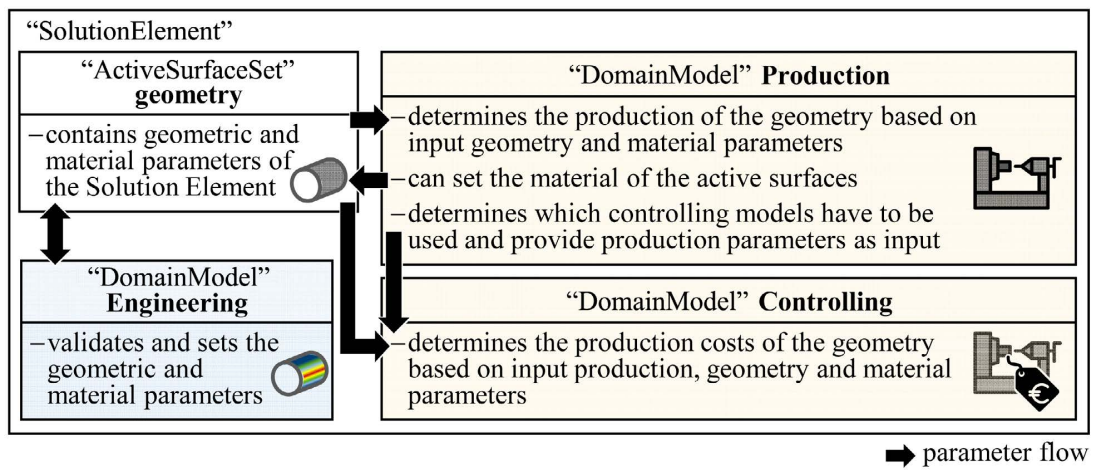

Figure 3. Extending MSE ARCHITECTURE meta model according to Jacobs et al. (2022) by Production and Controlling Models. 
the chain joint, the relevant production models for the geometries Cylinder and CylindricStructure are shown in Figure 4.

Relevant production models can be delimited in the first step by defining the production process of the active surfaces. In the running example the Cylinder surfaces are usually produced by round turning processes. This production process requires the use of a round steel as the raw material for the component CylindricStructure (see Figure 4, below). Relevant information related to this raw material include the available inventory and the calculation of the production parameter volume. The geometry parameters, such as the diameter of the active surfaces and the permitted surface pressure, directly influence the permitted dimensions and the material of the raw material.

The production models relevant for the Cylinder geometry are already constrained by the definition of the production process and raw material. In the running example, the specified models determine the selection of the longitudinal round turning production step (see Figure 4, below). In addition to the production step, the production resources and the associated tools are relevant for determining the production time $t_{h}$. The input parameters for calculating the production time depend directly on the raw material and tool production parameters as well as the active surface geometry parameter.

By identifying relevant information from the production domain, knowledge from production can already be made available to the engineering department for production planning of the geometries. Using the identified models, the

\begin{tabular}{|c|c|c|c|c|}
\hline \multicolumn{3}{|c|}{ "Component" CylindricStructure } & & \multirow[t]{2}{*}{ "SystemSolution" Chain Joint } \\
\hline \multicolumn{4}{|c|}{ "DomainModel" Production } & \\
\hline \multicolumn{4}{|c|}{$\begin{array}{c}\text { Production Model } \\
\text { inventory round steel }\end{array}$} & $\begin{array}{l}\text { Production Model } \\
\text { vol. calculation round raw material }\end{array}$ \\
\hline diameter & length & material & strength & \multirow{3}{*}{$V=\pi * \frac{d^{2}}{4} * l$} \\
\hline $35 \mathrm{~mm}$ & $2000 \mathrm{~mm}$ & structural steel & $340-510 \mathrm{~N} / \mathrm{mm}^{2}$ & \\
\hline$\ldots$ & $\ldots$ & $\ldots$ & $\ldots$ & \\
\hline
\end{tabular}

\begin{tabular}{|c|c|c|c|c|c|c|c|c|c|c|}
\hline \multicolumn{5}{|c|}{ "PhysicalEffect" HertzianPressure } & & & \multicolumn{4}{|c|}{ "SolutionElement" ClaeranceContact } \\
\hline \multicolumn{4}{|c|}{ "ActiveSurfaceSet" CylCyl } & \multicolumn{4}{|c|}{ "DomainModel" Engineering } & \multicolumn{3}{|c|}{ "DomainModel" Production } \\
\hline \multicolumn{7}{|c|}{ Production Model production steps innercyl } & \multicolumn{4}{|c|}{$\begin{array}{c}\text { Production Model } \\
\text { technical data production resources }\end{array}$} \\
\hline \multicolumn{2}{|l|}{ prod. step } & \multicolumn{3}{|c|}{ prod. resources } & \multicolumn{2}{|l|}{ prod. tools } & & & & \\
\hline \multirow{2}{*}{\multicolumn{2}{|c|}{$\begin{array}{l}\text { longitudinal } \\
\text { round turning }\end{array}$}} & \multirow{2}{*}{\multicolumn{3}{|c|}{$\begin{array}{l}\text { turning and } \\
\text { milling center }\end{array}$}} & \multirow{2}{*}{\multicolumn{2}{|c|}{$\begin{array}{l}\text { external turning } \\
\text { tool P10 }\end{array}$}} & \multicolumn{4}{|c|}{ technical data Lathe } \\
\hline & & & & & & & $\max . \mathrm{m}$ & ch. diameter & $\mathrm{mm}$ & 100 \\
\hline \begin{tabular}{|l}
$\cdots$ \\
\end{tabular} & & \multicolumn{3}{|l|}{$\cdots$} & \multicolumn{2}{|l|}{$\cdots$} & $\max . \mathrm{sp}$ & ndle speed & $1 / \mathrm{min}$ & 6000 \\
\hline \multicolumn{7}{|c|}{ Production Model technical data production tools } & $\ldots$ & & & \\
\hline \multicolumn{7}{|c|}{ cutting speed turning } & \multirow{2}{*}{\multicolumn{4}{|c|}{$\begin{array}{l}\text { Production Model } \\
\text { time calculation production step }\end{array}$}} \\
\hline \multirow{2}{*}{$\begin{array}{c}\text { strength } \\
\text { component }\end{array}$} & \multirow{2}{*}{\multicolumn{2}{|c|}{$\begin{array}{l}\text { cutting } \\
\text { material }\end{array}$}} & $a_{n}$ & \multicolumn{3}{|c|}{ feed rate $\mathrm{f}[\mathrm{mm}]$} & & & & \\
\hline & & & {$[\mathrm{mm}]$} & 0.1 & \multicolumn{2}{|l|}{\begin{tabular}{l|l|l|l|l}
0.16 & 0.25 \\
\end{tabular}} & \multirow{3}{*}{\multicolumn{4}{|c|}{$\begin{array}{c}t_{h}=\frac{V}{Q}=\frac{V}{a_{p} * f * v_{c}} \\
v_{c}=n_{c} * \pi * d\end{array}$}} \\
\hline \multirow{2}{*}{$400-500$} & \multicolumn{2}{|c|}{$\mathrm{P} 10$} & 1 & 450 & \begin{tabular}{|l|l|}
420 & 400 \\
\end{tabular} & & & & & \\
\hline & & & $\ldots$ & $\ldots$ & $\ldots$ & & & & & \\
\hline
\end{tabular}

Figure 4. Relevant production models for the "SystemSolution" Chain Joint (in reference to Paucksch et al., 2008, Dietrich, 2016). 
relevant production models can be selected from various data sources, when the geometry parameters are changed. Thereby, the design of the geometries can already be adapted according to production requirements.

\subsubsection{Formalization of the Production Models}

In order to be easily accessible in model-based development, the models must be formalized compatible with the MSE ARCHITECTURE. The formalization of the previously identified production models is based on the modeling language SysML. Basically, the models are divided into three sections-production processes, production resources and raw materials (Figure 5). The respective sections are structured in the classes production processes and steps, machine (groups) and tools as well as raw materials and the subordinate classes shape and material. The classification of the previously identified round turning production process, the longitudinal round turning production step and the round steel in this class is shown in Figure 5 for the running example.

The longitudinal round turning production step supplements the round turning production process with a production model for calculating the production time and with ports as an interface to the geometry parameters of the solution element. The modeling and classification of the production resources is carried out parallel to the classification of the production processes. The class lathe is assigned to the various machines of this type. By extending the model of the lathe, the turning and milling center owns the calculation constraint for calculating the material removal rate depending on the selected tool. A linking element is used to assign the production steps to the production resources. This linking

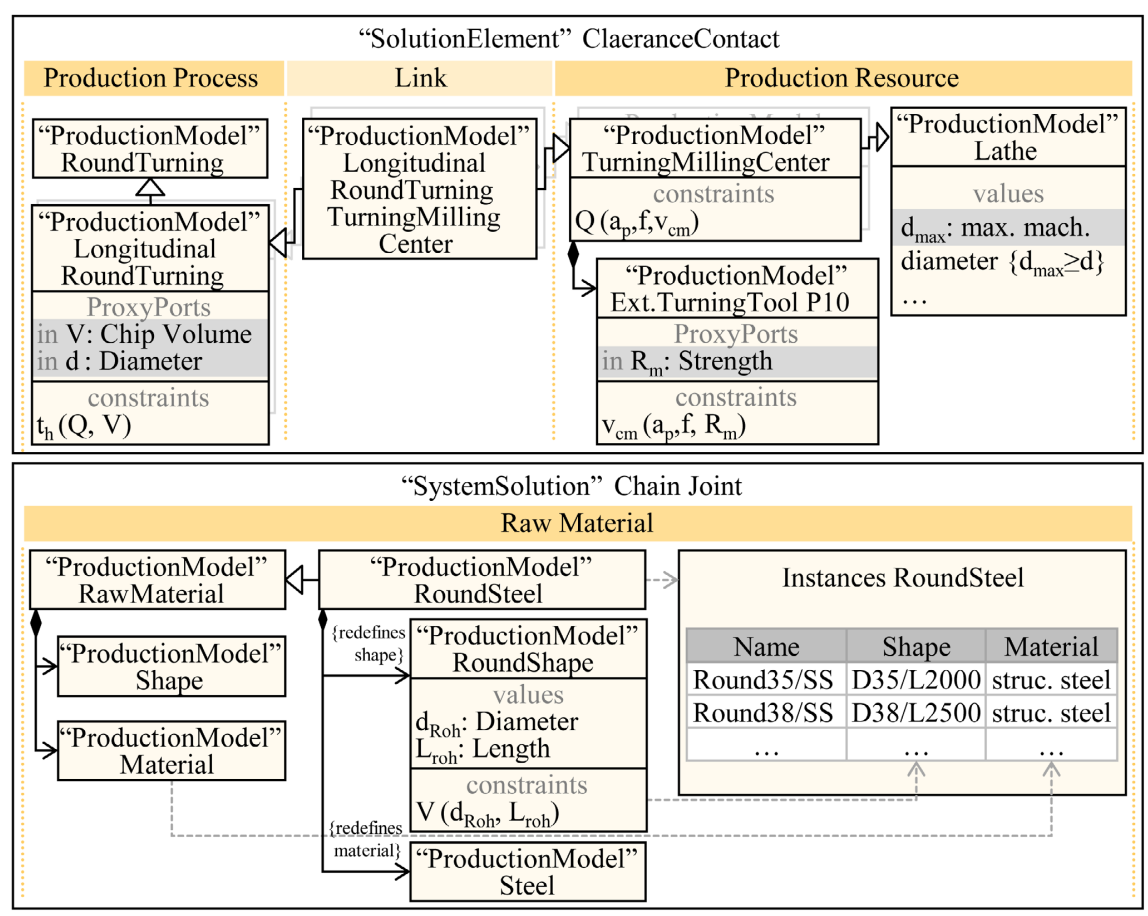

Figure 5. Formalization of the production models for the "SystemSolution" Chain Joint. 
element inherits the properties of the production resource and the assigned production step. Therefore, the properties of the production steps with regard to the individual resource can be modeled, new production resources can be integrated, and properties of the production resources can be adapted easily. Additional advantage of modeling in a class structure is that a single point of truth (SPOT) is created and the maintenance effort is reduced.

The formalization of the identified raw materials is carried out analogously via the definition of common relationships in a superordinate class raw material and the refinement of these. The specialized class round steel refines the superordinate class, by defining the material steel and the raw material form round shape. The inventory associated to the round steel is mapped via instance tables.

Advantages arise already in the systematic provision of the identified information in the engineering department. Through the formal description of the interrelationships, it is immediately visible which production steps, production resources and raw materials are currently available and suitable for the application. Using this information, the design of the products can already be adapted to production restrictions in the engineering department, which avoids iterations and thus increases efficiency in the development process.

\subsubsection{Identification of the Relevant Controlling Models}

With the help of the identified production models, raw materials and production steps can already be selected in the engineering department and thus the production parameters can be estimated manually. In order to determine the manufacturing costs, controlling models are also necessary. These models determine the product costs based on geometry and production parameters. Only by considering these models, the product costs can be calculated and compared with the target costs.

In development, the manufacturing costs of the product are particularly relevant. These result from the production and material costs. Inputs for the determination of the production cost include the volume of the raw material and the production time, whereas the volume of the raw material provides the input for calculating the material costs of the component. The production time supplies the necessary input for the calculation of the production costs of the solution element. Figure 6 presents the relevant models for the production and material cost calculation of the running example are indicated.

The production costs of the geometry arise from the costs of the individual production steps. For the Cylinder, these are only the production costs of the longitudinal round turning production step. According to Paucksch et al. (2008), the production costs for machining production steps consist of the primary time cost $K_{1}$, the fixed cost of the production resources and staff $K_{2}$ and the tool (change) cost $K_{3}$ (see Figure 6, left). Partial costs can be influenced in different amounts by changing production parameters, such as production time, adapting material parameters and selecting production resources. The material cost of the component result from the direct material cost $K_{M E}$ and the overhead material 
cost $K_{M G}$ (see Figure 6, right). These costs only depend on the production parameters of the raw material via the fixed overhead rate $g_{M}$ and the relative material cost $k_{V}$.

Generally, this identification method can be used to identify the controlling models beyond metal-cutting processes, such as additive manufacturing. However, the production and material costs vary according to the selected production process and the raw material. Identifying the production and resulting controlling models already provides the engineering department with relevant production and controlling knowledge. This permits geometries to be designed in line with production and cost requirements.

\subsubsection{Formalization of the Controlling Models}

In order to make the controlling models easily accessible in model-based development processes, they also need to be formalized. In Analogy to the formalization of the production models, the identified controlling models are formalized in three sections - production processes, production resources and raw materials (Figure 7).

\begin{tabular}{|c|c|c|c|c|c|}
\hline \multicolumn{2}{|c|}{ "SolutionElement" ClaeranceContact } & \multicolumn{4}{|c|}{ "SystemSolution" Chain Joint } \\
\hline $\begin{array}{l}\text { "DomainModel" } \\
\text { Production }\end{array}$ & $\begin{array}{c}\text { "DomainModel" } \\
\text { Controlling }\end{array}$ & \multicolumn{2}{|c|}{$\begin{array}{l}\text { "DomainModel" } \\
\text { Production }\end{array}$} & \multicolumn{2}{|c|}{$\begin{array}{c}\text { "DomainModel" } \\
\text { Controlling }\end{array}$} \\
\hline \multicolumn{2}{|c|}{$\begin{array}{l}\text { Controlling Model machining production cost } \\
K_{F}=K_{1}+K_{2}+K_{3}\end{array}$} & \multicolumn{4}{|c|}{$\begin{array}{l}\text { Controlling Model material cost } \\
K_{M}=K_{M E}+K_{M G}=\left(1+g_{M}\right) * K_{M E}\end{array}$} \\
\hline \multicolumn{2}{|c|}{$\begin{array}{l}\text { Controlling Model primary time cost } \\
K_{1}=\left(k_{M}+{ }^{k_{L}} / x\right) * t_{h}\end{array}$} & \multicolumn{4}{|c|}{$\begin{array}{l}\text { Controlling Model direct material cost } \\
K_{M E}=V * k_{V}\end{array}$} \\
\hline \multirow{2}{*}{\multicolumn{2}{|c|}{$\begin{array}{l}\text { Controlling Model fixed cost } \\
\begin{aligned} K_{2}= & 1 / m\left(k_{M}+k_{L}\right) *\left(t_{r M}+t_{r V}\right) \\
& +\left(k_{M}+{ }^{k_{L}} / x\right) *\left(t_{n}+t_{b}+t_{v B}\right)\end{aligned}\end{array}$}} & \multicolumn{4}{|c|}{$\begin{array}{c}\text { Controlling Model relative material cost } \\
\text { Round D 35-100 mm }\end{array}$} \\
\hline & & \multirow{2}{*}{ 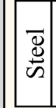 } & \multirow{2}{*}{\multicolumn{2}{|c|}{$\begin{array}{l}\text { structural steels } \\
\text { case-hardened steels } \\
\text { Q \& T steels } \\
\text {... } \\
\end{array}$}} & \multirow{2}{*}{$\begin{array}{l}\boxplus 1,0-1,1 \\
11,1-2,3 \\
\square 1,2-2,7\end{array}$} \\
\hline \multicolumn{2}{|c|}{$\begin{array}{l}\text { Controlling Model tool (change) cost } \\
K_{3}={ }^{t_{h}} /_{T}\left(k_{M}+k_{L}\right) * t_{W}+1 / m * K_{W}\end{array}$} & & & & \\
\hline
\end{tabular}

Figure 6. Relevant controlling models for the "SystemSolution" Chain Joint (in reference to Paucksch et al., 2008, Ehrlenspiel et al., 2014).
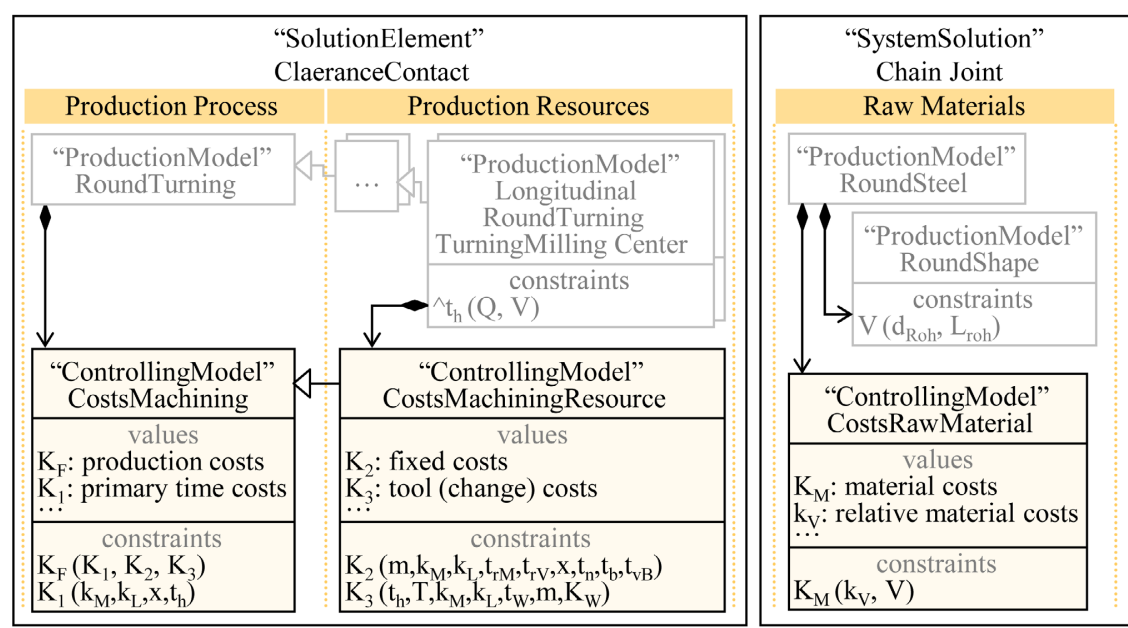

Figure 7. Formalization of the controlling models for the "SystemSolution" Chain Joint. 
Identified models are assigned to the respective sections. The assignment condition is, that the controlling models are assigned to the production models through which they are mainly caused. For example, tool (change) costs $K_{3}$ are mainly caused by the production resource and the associated production step and are therefore allocated to them. Advantages of this modeling arise in particular from the clear allocation of the individual controlling models to the cost-generating production models. The allocation also enables simple parameter value transfer to the respective controlling models.

By identifying and formalizing the relevant models, costs can already be calculated by selecting the models and manually entering the input parameters of the geometry. Thus, cost-relevant knowledge can be made available to the engineering department in a simple, formal and flexible adaptable form.

\subsection{Integrating Production and Controlling Models into the MSE ARCHITECTURE}

In order to achieve seamless value transfer and consistency, the models need to be integrated into the function-oriented product description analog to the defined MES ARCHITECTURE metamodel. The integration takes place within the system solution and the subordinate solution elements. Figure 8 shows the integration of the previously formalized models into the system solution chain joint.

Within the solution element, the production models and the associated controlling models of each active surface are modeled collectively in the production plan. In the running example, the production plan of the active surfaces $C y l i n d-$ er consists of the production model LongitudinalRoundTurning TurningMillingCenter and the associated controlling model CostsMachiningResource. The geometry parameters are linked via the interfaces which are defined for the

"SolutionElement" ClaeranceContact

Figure 8. Integrating production and controlling models into the MSE ARCHITECTURE for the "SystemSolution" Chain Joint. 
models. The domain models of the system solution are connected via the production model Round Steel. This model contains the production models RoundShape and Steel as well as the controlling model CostRawMaterial.

Through the integration of the domain models into the system solution, seamless parametric linkage of the controlling and production models to the digital product description is possible and thus an automated, direct provision of cost information during concept development. This enables a direct comparison of the manufacturing costs with the target costs defined in the requirements. As a result, the product design can be adapted and optimized earlier and faster based on current information. Potential cost reductions located in the development department can thus be exploited.

\section{Conclusion}

Especially for companies that are facing international competition, the consideration of costs early in the development process is an issue of great concern. Therefore, the goal of the presented approach is to provide cost-relevant knowledge in product development. Based on the geometries of the solution element and the system solution, the relevant models could be identified. The provision of knowledge was made possible by linking production and controlling models to the MSE ARCHITECTURE. With the help of the language SysML and extending the language profile SysML4FMArch, the models could be formalized and integrated into the MSE ARCHITECTURE. As a result, the approach allows to provide cost information of the current design already within the development. Based on this information, the developer is directly informed whether the target costs are met. When the target costs are not met, countermeasures can be taken early in the process, thus avoiding iterations. A further advantage is, that according to Ehrlenspiel et al. (2014), the production costs can be reduced by 10 to 30 percent through the collaborative cost optimization by engineering, production and controlling. The costs can be reduced even further, if the product concepts are adapted in the MSE ARCHITECTURE solutions.

Disadvantage of considering controlling and production domains in addition to the engineering domain within the product development is that the complexity of the system model increases with the number of models. To address this deficit, a necessary next step is to develop an approach which reduces the complexity of integrating a large number of models into the system model. The partially automated control of the production and controlling models as well as the optimization of the geometry parameters with regard to the costs should also be strived for. This could exploit potentials for cost reduction in development and lead to a permanent reduction in product costs.

\section{Conflicts of Interest}

The authors declare no conflicts of interest regarding the publication of this paper. 


\section{References}

Anderson, D. M., \& Pine, J. (1998). Agile Product Development for Mass Customization. How to Develop and Deliver Products for Mass Customization, Niche Markets, JIT, Build-to-Order, and Flexible Manufacturing. McGraw-Hill.

Dietrich, J. (2016). Praxis der Zerspantechnik(12th ed.). Springer Fachmedien. https://doi.org/10.1007/978-3-658-14053-3

Drave, I., Rumpe, B., Wortmann, A., Berroth, J., Hoepfner, G., Jacobs, G., Spütz, K. et al. (2020). Modeling Mechanical Functional Architectures in SysML. In E. Syriani \& H. Sahraoui (Eds.), Proceedings of the 23rd ACM/IEEE International Conference on Model Driven Engineering Languages and Systems (pp. 79-89). Association for Computing Machinery. https://doi.org/10.1145/3365438.3410938

Ehrlenspiel, K., Kiewert, A., Lindemann, U., \& Mörtl, M. (2014). Kostengünstig Entwickeln und Konstruieren (7th ed.). Springer-Verlag. https://doi.org/10.1007/978-3-642-41959-1

Eigner, M., Roubanov, D., \& Zafirov, R. (2014). Modellbasierte virtuelle Produktentwicklung. Springer-Verlag. https://doi.org/10.1007/978-3-662-43816-9

Eigner, M., \& Stelzer, R. (2009). Product Lifecycle Management (2nd ed.). Springer-Verlag. https://doi.org/10.1007/b93672

Friedli, T., \& Schuh, G. (2012). Wettbewerbsfähigkeit der Produktion an Hochlohnstandorten (2nd ed.). Springer-Verlag. https://doi.org/10.1007/978-3-642-30276-3

Höpfner, G., Jacobs, G., Zerwas, T., Drave, I., Berroth, J., Guist, C., Rumpe, B. et al. (2021). Model-Based Design Workflows for Cyber-Physical Systems Applied to an Electric-Mechanical Coolant Pump. IOP Conference Series: Materials Science and Engineering, 1097, Article ID: 012004. https://doi.org/10.1088/1757-899X/1097/1/012004

Jacobs, G., Konrad, C., Berroth, J.K., Zerwas, T., Höpfner, G., \& Spütz, K. (2022). Function-Oriented Model-Based Product Development. In D. Krause \& E. Heyden (Eds.), Methodenbuch. Wissenschaftlichen Gesellschaft für Produktentwicklung (WiGeP).

Moeser, G., Grundel, M., Weilkiens, T., Kümpel, S., Kramer, C., \& Albers, A. (2016). Modellbasierter mechanischer Konzeptentwurf: Ergebnisse des FAS4M-Projektes. In S. O. Schulze, C. Tschirner, R. Kaffenberger, \& S. Ackva (Eds.), Tag des Systems Engineering 2016 (pp. 419-428). Carl Hanser Verlag. https://doi.org/10.3139/9783446451414.040

Verband Deutscher Maschinen- und Anlagenbauer (VDMA) (2006). Kennzahlenkompass 2002. Maschinenbau-Verlag.

Verband Deutscher Maschinen- und Anlagenbauer (VDMA) (2018). Das Chinageschäft der Zukunft-Herausforderungen und Strategien für den deutschen Maschinenbau. https://ea.vdma.org/viewer/-/v2article/render/27009603

Verein Deutscher Ingenieure (1987). VDI-Richtlinie 2235: Wirtschaftliche Entscheidungen beim Konstruieren. VDI-Verlag.

Weilkiens, T. (2016). SYSMOD-The Systems Modeling Toolbox-Pragmatic MBSE with SysML (2nd ed.). Tim Weilkiens.

Zerwas, T., Jacobs, G., Spütz, K., Höpfner, G., Drave, I., Berroth, J., Guist, C. et al. (2021). Mechanical Concept Development Using Principle Solution Models. IOP Conference Series: Materials Science and Engineering, 1097, Article ID: 012001. https://doi.org/10.1088/1757-899X/1097/1/012001

Paucksch, E., Holsten, S., Linß, M., \& Tikal, F. (2008). Zerspantechnik: Prozesse, Werkzeuge, Technologien (12th ed.). Springer-Verlag. 